\title{
Front Matter: Volume 7712
}

, "Front Matter: Volume 7712," Proc. SPIE 7712, Nanophotonics III, 771201 (21 May 2010); doi: 10.1117/12.865621

SPIE. Event: SPIE Photonics Europe, 2010, Brussels, Belgium 


\title{
PROCEEDINGS OF SPIE
}

\section{Nanophotonics III}

\author{
David L. Andrews \\ Jean-Michel Nunzi \\ Andreas Ostendorf \\ Editors
}

12-16 April 2010

Brussels, Belgium

Sponsored by

SPIE

Cosponsored By

B-PHOT—Brussels Photonics Team (Belgium) - Brussels-Capital Region (Belgium) • FWO_Fonds Wetenschappelijk Onderzoek (Belgium) • ICO_International Commission for Optics $\bullet$ Ville de Bruxelles (Belgium)

Cooperating Organisations

CBO-BCO (Belgium) • EOS-European Optical Society (Germany) • IET-The Institution of Engineering and Technology (United Kingdom) • IOP-Institute of Physics (United Kingdom) Photonics4Life (Germany) Photonics@be (Belgium) • Photonics 21 (Germany) • PromOptica (Belgium)

Published by

SPIE

Volume 7712

Proceedings of SPIE, 0277-786X, v. 7712 
The papers included in this volume were part of the technical conference cited on the cover and title page. Papers were selected and subject to review by the editors and conference program committee. Some conference presentations may not be available for publication. The papers published in these proceedings reflect the work and thoughts of the authors and are published herein as submitted. The publisher is not responsible for the validity of the information or for any outcomes resulting from reliance thereon.

Please use the following format to cite material from this book:

Author(s), "Title of Paper," in Nanophotonics III, edited by David L. Andrews, Jean-Michel Nunzi, Andreas Ostendorf, Proceedings of SPIE Vol. 7712 (SPIE, Bellingham, WA, 2010) Article CID Number.

ISSN 0277-786X

ISBN 9780819481856

Published by

SPIE

P.O. Box 10, Bellingham, Washington 98227-0010 USA

Telephone +1 3606763290 (Pacific Time) · Fax +1 3606471445

SPIE.org

Copyright (c) 2010, Society of Photo-Optical Instrumentation Engineers

Copying of material in this book for internal or personal use, or for the internal or personal use of specific clients, beyond the fair use provisions granted by the U.S. Copyright Law is authorized by SPIE subject to payment of copying fees. The Transactional Reporting Service base fee for this volume is $\$ 18.00$ per article (or portion thereof), which should be paid directly to the Copyright Clearance Center (CCC), 222 Rosewood Drive, Danvers, MA 01923. Payment may also be made electronically through CCC Online at copyright.com. Other copying for republication, resale, advertising or promotion, or any form of systematic or multiple reproduction of any material in this book is prohibited except with permission in writing from the publisher. The CCC fee code is 0277-786X/10/\$18.00.

Printed in the United States of America.

Publication of record for individual papers is online in the SPIE Digital Library.

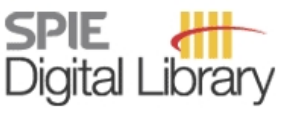

SPIEDigitalLibrary.org

Paper Numbering: Proceedings of SPIE follow an e-First publication model, with papers published first online and then in print and on CD-ROM. Papers are published as they are submitted and meet publication criteria. A unique, consistent, permanent citation identifier (CID) number is assigned to each article at the time of the first publication. Utilization of CIDs allows articles to be fully citable as soon they are published online, and connects the same identifier to all online, print, and electronic versions of the publication. SPIE uses a six-digit CID article numbering system in which:

- The first four digits correspond to the SPIE volume number.

- The last two digits indicate publication order within the volume using a Base 36 numbering system employing both numerals and letters. These two-number sets start with 00, 01, 02, 03, 04 , $05,06,07,08,09,0 A, 0 B \ldots$. OZ, followed by 10-1Z, 20-2Z, etc.

The CID number appears on each page of the manuscript. The complete citation is used on the first page, and an abbreviated version on subsequent pages. Numbers in the index correspond to the last two digits of the six-digit CID number. 


\section{Contents}

ix Conference Committee

xi Introduction

\section{PLASMONICS I}

771204 Requirements for a rectifying antenna solar cell technology [7712-03]

J. M. Nunzi, XLIM CNRS, Univ. de Limoges (France) and Queen's Univ. (Canada)

\section{PLASMONICS II}

771209 Theoretical modelling and leakage radiation microscopy of surface plasmon polariton excitation and scattering on laser fabricated surface structures [7712-08] C. Reinhardt, A. I. Kuznetsov, A. B. Evlyukhin, W. Cheng, A. Seidel, B. N. Chichkov, Laser Zentrum Hannover e.V. (Germany)

$77120 \mathrm{~A}$ Compact integrated optical isolation based on extraordinary dichroic transmission through a magnetoplasmonic waveguide grating [7712-09]

M. Vanwolleghem, L. Magdenko, P. Beauvillain, B. Dagens, Institut d'Électronique

Fondamentale, CNRS, Univ. Paris 11 (France)

$7712 \mathrm{OB}$ Negative permittivity chamber inside a stack of silver nanorings [7712-10]

S. C. Chen, J. C. Shiu, Far East Univ. (Taiwan)

7712 OC Hybridized exciton-plasmon polaritons in nanostructured silver films [7712-11]

N. Cade, T. Ritman-Meer, D. Richards, King's College London (United Kingdom)

\section{OPTICAL NANOFABRICATION I}

7712 OE 3D harnessing of light with photon cage [7712-13]

C. Sieutat, J. L. Leclerca, X. Letartre, S. Callard, M. Gendry, G. Grenet, K. Naji, P. Regreny, P. Rojo-Romeo, P. Viktorovitch, Institut des Nanotechnologies de Lyon, CNRS, Univ. de Lyon (France); G. Beaudin, M. Cloutier, D. Drouin, V. Aimez, Univ. de Sherbrooke (Canada)

$77120 F \quad$ Polarization- and wavelength-sensitive sub-wavelength structures fabricated in the metal layers of deep submicron CMOS processes [7712-14]

S. Junger, W. Tschekalinskij, N. Verwaal, N. Weber, Fraunhofer Institute for Integrated Circuits (Germany)

$7712 \mathrm{OH}$ Silica nano-ridges connections based on a fluidic approach for hybrid integrated photonics [7712-16]

B. Bêche, A. Jimenez, L. Courbin, IPR, CNRS, Univ. Rennes 1 (France); L. Camberlein, LAUM, CNRS, Univ. du Maine (France); F. Doré, D. Duval, F. Artzner, IPR, CNRS, Univ. Rennes 1

(France); E. Gaviot, LAUM, CNRS, Univ. du Maine (France) 
$7712 \mathrm{OL}$ Influence of the roughness of metal templates on surface enhanced Raman scattering [7712-20]

M. R. Gonçalves, O. Marti, Ulm Univ. (Germany)

\section{OPTICAL NANOFABRICATION II}

7712 OP Plasmon resonances of gold nanostars [7712-24]

L. Raguin, Swiss Federal Institute of Technology (Switzerland); T. Samrowski, Univ. Zürich

(Switzerland); C. Hafner, R. Vahldieck, Swiss Federal Institute of Technology (Switzerland)

$77120 Q \quad$ Controlling the optical properties of quantum emitters by optical confinement in a tunable microcavity (Best Student Paper Award) [7712-25]

R. Gutbrod, A. I. Chizhik, A. M. Chizhik, D. Khoptyar, S. Bär, A. J. Meixner, Univ. of Tuebingen (Germany)

\section{NEAR-FIELD OPTICS AND IMAGING II}

$77120 Z \quad$ Near-field scanning single-photon microscopy with an ultrasmall nanodiamond: How good can the resolution be? [7712-34]

A. Drezet, A. Cuche, O. Mollet, S. Huant, Institut Néel, CNRS, Univ. Joseph Fourier (France)

771211 GaAs micro-nanodisks probed by a looped fiber taper for optomechanics applications [7712-36]

L. Ding, Lab. Matériaux et Phénomènes Quantiques, CNRS, Univ. Paris Diderot (France);

P. Senellart, A. Lemaitre, Lab. de Photonique et de Nanostructures (France); S. Ducci,

G. Leo, I. Favero, Lab. Matériaux et Phénomènes Quantiques, CNRS, Univ. Paris Dideroł (France)

\section{OPTICAL NANOMANIPULATION I}

771212 Small scale de-excitation and entanglement near surfaces in open cavity quantum optics (Invited Paper) [7712-37]

M. Babiker, The Univ. of York (United Kingdom); S. C. Skipsey, The Univ. of Glasgow (United Kingdom)

771213 Manipulation of surface plasmons on a vertical cavity surface emitting laser platform [7712-38]

B. Corbett, J.-M. Lamy, J. Justice, G. Lévêque, Univ. College Cork (Ireland)

771214 Fast localized modes propagating in optical metal coaxial waveguides [7712-39] O. N. Kozina, Saratov Branch of the Institute of Radio Engineering and Electronics (Russian Federation); L. A. Melnikov, Saratov State Univ. (Russian Federation); I. S. Nefedov, Helsinki Univ. of Technology (Finland)

771215 A novel approach for the preparation of discrete phosphor nanoparticles [7712-40]

R. Withnall, S. Hajare, S. Zhang, G. R. Fern, T. G. Ireland, J. Silver, Brunel Univ. (United Kingdom) 
771217 Photomechanical effect of azobenzene thin polymer films measured with an AFM cantilever based sensor (Invited Paper) [7712-42]

Z. S. Mahimwalla, Y. Ngai, C. J. Barrett, McGill Univ. (Canada)

771219 Optical binding between polar particles [7712-44]

L. C. Dávila Romero, S. N. A. Smith, D. L. Andrews, Univ. of East Anglia Norwich (United Kingdom)

\section{PLASMONICS IV}

$77121 \mathrm{E} \quad$ Enhanced quadrupolar second-harmonic generation from rough gold films [7712-49] F. X. Wang, F. J. Rodríguez, Tampere Univ. of Technology (Finland); W. M. Albers, VTT Microtechnology and Sensors (Finland); M. Kauranen, Tampere Univ. of Technology (Finland)

\section{PLASMONICS V}

771211 Theoretical study of surface plasmon frequencies in a system of two coupled spheres and comparison with experimental data [7712-53]

T. Makaryan, Yerevan State Univ. (Armenia); K. Madoyan, A. Melikyan, Russian-Armenian (Slavonic) State Univ. (Armenia); H. Minassian, Yerevan Physics Institute (Armenia)

\section{NONLINEAR OPTICS}

771210 Effective medium multipolar tensor analysis of second-harmonic generation from metal nanoparticles [7712-59]

M. Zdanowicz, Tampere Univ. of Technology (Finland) and National Institute of Telecommunications (Poland); S. Kujala, H. Husu, M. Kauranen, Tampere Univ. of Technology (Finland)

7712 IR Controlling nanoscale optical emission with off-resonant laser light [7712-62]

D. L. Andrews, J. M. Leeder, D. S. Bradshaw, Univ. of East Anglia Norwich (United Kingdom)

\section{PLASMONICS VI}

$77121 \mathrm{~T} \quad$ High resolution surface plasmon imaging of nanoparticles [7712-64]

L. Berguiga, Univ. de Lyon (France) and Lab. Joliot Curie, CNRS, Univ. Bordeaux 1 (France);

T. Roland, A. Fahys, Univ. de Lyon (France), Lab. Joliot Curie, CNRS, Univ. Bordeaux 1 (France), and Lab. de Physique, CNRS, Univ. Bordeaux 1 (France); J. Elezgaray, ENITAB, CNRS, Univ. Bordeaux 1 (France); F. Argoul, Univ. de Lyon (France), Lab. Joliot Curie, CNRS, Univ. Bordeaux 1 (France), and Lab. de Physique, CNRS, Univ. Bordeaux 1 (France)

$77121 \mathrm{~V}$ Exploring the role of the surface states in the luminescence of gold spherical particles by single molecule spectroscopy [7712-66]

M. Loumaigne, A. Débarre, Lab. Aime Cotton, CNRS, Univ. Paris-Sud (France) 
$77121 \mathrm{X} \quad$ Rigorous characterization of surface plasmon modes by using the finite element method [7712-68]

B. M. A. Rahman, N. Kejalakshmy, H. Tanvir, A. Quadir, K. T. V. Grattan, City Univ. London (United Kingdom)

771221 Optical micro resonance based sensor schemes for detection and identification of nano particles and biological agents in situ [7712-72]

V. A. Saetchnikov, E. A. Tcherniavskaia, Belarusian State Univ. (Belarus); G. Schweiger,

A. Ostendorf, Ruhr-Univ. Bochum (Germany)

771222 Ultrasharp carbon whisker optical fiber probes for scanning near-field optical microscopy [7712-73]

M. Mensi, Ecole Polytechnique Fédérale de Lausanne (Switzerland); G. Mikhailov, S. Pyatkin, Institute of Microelectronics Technology and High Purity Materials (Russian Federation); J. Adamcik, Ecole Polytechnique Fédérale de Lausanne (Switzerland); S. Sekatskii, Ecole Polytechnique Fédérale de Lausanne (Switzerland) and Institute of Spectroscopy (Russian Federation); G. Dietler, Ecole Polytechnique Fédérale de Lausanne (Switzerland)

771224 Dual-channel radially-polarized surface plasmon microscopy for simultaneous detection of fluorescence and linear scattering of nanospheres [7712-75]

C.-H. Sung, Lab. de Photonique Quantique et Moléculaire, Institut d'Alembert, Ecole Normale Supérieure de Cacha (France) and National Taiwan Univ. (Taiwan); D. Chauvat, J. Zyss, Lab. de Photonique Quantique et Moléculaire, Institut d'Alembert, Ecole Normale Supérieure de Cacha (France); C.-K. Lee, National Taiwan Univ. (Taiwan)

771225 Optical characteristics of the two-dimensional photonic crystals with nano-size metal roads [7712-76]

O. N. Kozina, Institute of Radio Engineering and Electronics (Russian Federation);

L. A. Melnikov, Saratov State Technical Univ. (Russian Federation)

7712 2A Controlled rotation of lipid tubules with optical tweezers [7712-82]

S. Charrunchon, Kasetsart Univ. (Thailand); S. Sumriddetchkajorn, National Electronics and Computer Technology Ctr. (Thailand); J. Limtrakul, N. Chattham, Kasetsart Univ. (Thailand) and Kasetsart Univ. Research and Development Institute (Thailand)

7712 2J Nonlinear optical properties of BSO nanoparticles dispersed in PMMA matrix [7712-92] H. Sekhar, P. Prem Kiran, D. Narayana Rao, Univ. of Hyderabad (India)

$77122 \mathrm{~K}$ On the definition of beam width of highly-focused radially-polarized light fields [7712-93] R. Martínez-Herrero, P. M. Mejías, Univ. Complutense de Madrid (Spain); A. Manjavacas, Instituto de Óptica, CSIC (Spain)

$77122 R \quad$ Broadband plasmonic couplers for light trapping and waveguiding [7712-101]

F. Djidjeli, E. Jaberansary, H. M. H. Chong, D. M. Bagnall, Univ. of Southampton (United Kingdom) 
771225 Dynamically optical response of silver nanoparticle film under an annealing treatment [7712-102]

W.-C. Hung, T.-K. Liu, I-M. Jiang, National Sun Yat-Sen Univ. (Taiwan); M.-S. Tsai, National Chiayi Univ. (Taiwan); P. Yeh, Univ. of California, Santa Barbara (United States); W.-H. Cheng, National Sun Yat-Sen Univ. (Taiwan)

$77122 \mathrm{~V}$ Femtosecond laser nanostructuring of metals: sub100-nm one-dimensional surface gratings [7712-105]

E. V. Golosov, Belgorod State Univ. (Russian Federation); A. A. Ionin, P.N. Lebedev Physical Institute (Russian Federation); Yu. R. Kolobov, Belgorod State Univ. (Russian Federation); S. I. Kudryashov, P.N. Lebedev Physical Institute (Russian Federation); A. E. Ligachev, A.M. Prokhorov General Physics Institute (Russian Federation); Yu. N. Novoselov, L. V. Seleznev, D. V. Sinitsyn, A. R. Sharipov, P.N. Lebedev Physical Institute (Russian Federation)

$77122 \mathrm{Y}$ Surface plasmon polariton excitation and extraordinary optical transmission in metallic grating structures with subwavelength slits [7712-108]

V. E. Babicheva, Moscow Institute of Physics and Technology (Russian Federation);

Y. E. Lozovik, Institute for Spectroscopy (Russian Federation)

$77122 Z$ Characterization of laser-written dielectric-loaded surface plasmon polariton waveguides by leakage radiation microscopy [7712-109]

C. Reinhardt, A. Seidel, W. Cheng, A. B. Evlyukhin, B. N. Chichkov, Laser Zentrum Hannover e.V. (Germany)

771231 Nanoscale plasmonic waveguides for filtering and demultiplexing devices [7712-111] A. Akjouj, A. Noual, Y. Pennec, B. Bjafari-Rouhani, Institut d'Electronique, de Microélectronique, et de Nanotechnologie, CNRS, Univ. de Lille 1 (France)

771234 Mechanism of photoluminescence investigation of Si nano-crystals embedded in SiOx [7712-114]

A. Vivas Hernández, ESIME-National Polyłechnic Institute (Mexico); T. V. Torchynska, ESFM-National Polytechnic Institute (Mexico); I. Guerrero Moreno, UPIITA-National Polytechnic Institute (Mexico)

771235 Theoretical and experimental study of the short and long range sensing using gold nanostructures [7712-115]

S. Szunerits, Institut d'Electronique, de Microélectronique et de Nanotechnologie, CNRS, Univ. de Lille 1 (France) and Institut de Recherche Interdisciplinaire (France); O. Saison, A. Akjouj, Y. Pennec, B. Djafari-Rouhani, Institut d'Electronique, de Microélectronique et de Nanotechnologie, CNRS, Univ. de Lille 1 (France); E. Galopin, J. Niedziołka-Jönsson, R. Boukherroub, Institut d'Electronique, de Microélectronique et de Nanotechnologie, CNRS, Univ. de Lille 1 (France) and Institut de Recherche Interdisciplinaire (France)

771236 Controlling molecular organization at the nanoscale for localized second harmonic generation [7712-116]

I. Berline, L. Douillard, F. Charra, C. Fiorini-Debuisschert, CEA-IRAMIS, SPCSI, Nanophotonics Lab. (France) 
771238 Enhanced transmission of s-polarized light through a metal slit [7712-118]

M. Guillaumée, Swiss Ctr. for Electronics and Microtechnology (Switzerland); A. Yu. Nikitin, Univ. de Zaragoza (Spain); L. A. Dunbar, V. Spassov, M. J. K. Klein, R. Eckert, Swiss Ctr. for Electronics and Microtechnology (Switzerland); L. Martín-Moreno, Univ. de Zaragoza (Spain); F. J. García-Vidal, Univ. Autonoma de Madrid (Spain); R. P. Stanley, Swiss Ctr. for Electronics and Microtechnology (Switzerland)

771239 Nanostructured metallic surfaces for enhanced transmission and polarization filtering in CMOS fabricated photodetectors [7712-119]

L. A. Dunbar, M. Guillaumée, Ctr. Suisse d'Electronique et de Microtechnique SA

(Switzerland); F. de León-Pérez, Univ. de Zaragoza (Spain); P.-F. Rüedi, V. Spassov, R. Eckert, Ctr. Suisse d'Electronique et de Microtechnique SA (Switzerland); F. Lopez-Tejeira, Univ. de Zaragoza (Spain); F. J. García-Vidal, Univ. Autónoma de Madrid (Spain); E. Franzi, Ctr. Suisse d'Electronique et de Microtechnique SA (Switzerland); L. Martín-Moreno, Univ. de Zaragoza (Spain); R. P. Stanley, Ctr. Suisse d'Electronique et de Microtechnique SA (Switzerland)

$77123 \mathrm{~A} \quad$ Optically induced three-dimensional photonic lattices and quasi-crystallographic structures [7712-120]

J. Becker, Westfälische Wilhelms-Univ. Münster (Germany); J. Xavier, Indian Institute of Technology Delhi (India); M. Boguslawski, P. Rose, Westfälische Wilhelms-Univ. Münster (Germany); J. Joseph, Indian Institute of Technology Delhi (India); C. Denz, Westfälische Wilhelms-Univ. Münster (Germany)

7712 3D Two-photon transitions in triazole based quadrupolar and octupolar chromophores: a TD-DFT investigation [7712-123]

C. Katan, CNRS, Univ. de Rennes 1 (France) and CNRS, INSA de Rennes, Fonctions Optiques pour les Technologies de I'Information (France); S. Tretiak, Ctr. for NonLinear Studies (United States) and Ctr. for Integrated NanoTechnologies (United States); J. Even, CNRS, INSA de Rennes, Fonctions Optiques pour les Technologies de l'Information (France)

Author Index 


\title{
Conference Committee
}

\author{
Symposium Chairs
}

Francis Berghmans, Vrije Universiteit Brussel (Belgium)

Ronan Burgess, European Commission (Belgium)

Jürgen Popp, Institute of Photonic Technology Jena e.V. (Germany)

Peter Hartmann, SCHOTT AG (Germany)

Hugo Thienpont, Vrije Universiteit Brussel (Belgium)

Conference Chairs

David L. Andrews, University of East Anglia Norwich (United Kingdom)

Jean-Michel Nunzi, Queen's University (Canada)

Andreas Ostendorf, Ruhr-Universität Bochum (Germany)

Program Committee

Fabrice Charra, Commissariat à l'Énergie Atomique (France)

Alain Dereux, Université de Bourgogne (France)

Aleksandra B. Djurisic, The University of Hong Kong (Hong Kong, China)

Yuval Golan, Ben-Gurion University of the Negev (Israel)

Dirk M. Guldi, Friedrich-Alexander-Universität Erlangen-Nürnberg (Germany)

Satoshi Kawata, Osaka University (Japan)

Martti Kauranen, Tampere University of Technology (Finland)

Karsten König, JenLab GmbH (Germany)

Manijeh Razeghi, Northwestern University (United States)

Carsten Reinhardt, Laser Zentrum Hannover e.V. (Germany)

Gary P. Wiederrecht, Argonne National Laboratory (United States)

Anatoly V. Zayats, Queen's University Belfast (United Kingdom)

\section{Session Chairs}

1 Plasmonics 1

David L. Andrews, University of East Anglia Norwich (United Kingdom)

2 Plasmonics II

Jean-Michel Nunzi, Queen's University (Canada)

3 Optical Nanofabrication I

Yuval Golan, Ben-Gurion University of the Negev (Israel) 
4 Plasmonics III

Martti Kauranen, Tampere University of Technology (Finland)

5 Optical Nanofabrication II

David L. Andrews, University of East Anglia Norwich (United Kingdom)

$6 \quad$ Near-Field Optics and Imaging I

David L. Andrews, University of East Anglia Norwich (United Kingdom)

$7 \quad$ Near-Field Optics and Imaging II

David L. Andrews, University of East Anglia Norwich (United Kingdom)

8 Optical Nanomanipulation I

Jean-Michel Nunzi, Queen's University (Canada)

9 Optical Nanomanipulation II

Jean-Michel Nunzi, Queen's University (Canada)

10 Plasmonics IV

Anatoly V. Zayats, Queen's University Belfast (United Kingdom)

11 Plasmonics $V$

Carsten Reinhardt, Laser Zentrum Hannover e.V. (Germany)

12 Nanoparticles

Andreas Ostendorf, Ruhr-Universität Bochum (Germany)

13 Nonlinear Optics

Andreas Ostendorf, Ruhr-Universität Bochum (Germany)

14 Plasmonics VI

Céline Fiorini-Debuisschert, Commissariat à l'Énergie Atomique (France) 


\section{Introduction}

The Photonics Europe conference on Nanophotonics is now firmly established on the international research stage. This year's conference, the third in the biennial series, ran a full week with a packed schedule of high quality lecture and poster sessions. The presentations represented the full span of a fast-moving and highly distinctive subject area. Invited and contributory participants were drawn to the new venue in Brussels from far afield, many of those who travelled the furthest subsequently falling foul of the prolonged flight groundings that followed the eruption of Eyjafjallajökull in Iceland. Such were their enforced delays in returning home, two weeks in some cases, that a number of our contributors ran short of time to deliver a manuscript to these proceedings. To them we offer our appreciative thanks for their presence and all of their other contributions at the conference, and for enduring with good spirit the problems that thereafter beset them.

The concise and still relatively new term, 'nanophotonics,' addresses the many physical systems and optical interactions in which characteristics are very substantially modified, in some cases almost entirely determined, by nanoscale features. Here, the character of optical propagation and measurement commonly involves an intricate interplay of structural, spectroscopic, electromagnetic, electronic, and quantum optical features. An increasingly extensive range of structures is being actively researched. Many of the active research themes concern surfaces either directly or indirectly, for example nanofabricated surfaces and surface plasmonics, thin film optics, near-field interactions, evanescent waves and sub-wavelength aperture effects. Other kinds of response are manifest in supramolecular and polymeric systems, cavity nanophotonic structures, and nano-antennas. All are represented in these proceedings.

It is a pleasure to thank all who contributed to the meeting; those who presented papers and delivered high quality manuscripts for these proceedings, and fellow members of the program committee who chaired sessions and generally helped draw the conference together. Finally we record sincere thanks to all of the members of SPIE support staff, for uncompromising and characteristic professionalism, enthusiasm, and above all for their keen support.

David L. Andrews Jean-Michel Nunzi Andreas Ostendorf 
Downloaded From: https://www.spiedigitallibrary.org/conference-proceedings-of-spie on 26 Apr 2023

Terms of Use: https://www.spiedigitallibrary.org/terms-of-use 